\title{
Broncopneumonia refratária por antibioticoterapia inadequada em cão
}

\author{
[Refractory bronchopneumonia due to inadequate antibiotic therapy in dogs]
}

\section{"Relato de Caso/Case Report"}

\author{
Juliana Silva do Carmo ${ }^{1 *}$, Mário dos Santos Filho $^{2}$, Daniel Carvalho Hainfellner², \\ Bruno Ricardo Soares Alberigi ${ }^{2}$, Diana do Amaral Mendonça ${ }^{1}$, \\ Mateus Fernando Senra de Almeida ${ }^{1}$, Jonimar Pereira Paiva ${ }^{3}$
}

\begin{abstract}
${ }^{1}$ Hospital Veterinário de Pequenos Animais, Universidade Federal Rural do Rio de Janeiro, Seropédica-RJ, Brasil.
${ }^{2}$ Programa de Pós-Graduação em Medicina Veterinária, Universidade Federal Rural do Rio de Janeiro, Seropédica-RJ, Brasil.

${ }^{3}$ Departamento de Medicina e Cirurgia Veterinária, Universidade Federal Rural do Rio de Janeiro, Seropédica-RJ, Brasil. *Autor para correspondência/Corresponding author: E-mail: docarmo.julianas@gmail.com
\end{abstract}

\section{Resumo}

Afecções do aparelho respiratório inferior são rotineiras na clínica de pequenos animais e possuem diversas etiologias sendo necessária, portanto, precisão no momento da identificação dos agentes envolvidos, que acarretará em intervenções adequadas caso a caso. O lavado broncoalveolar (LBA) constitui-se como importante meio diagnóstico que pode ser utilizado em animais com broncopneumonia que não respondem a terapia padrão. Apesar do LBA ser uma técnica simples, o mesmo não é rotineiramente utilizado na medicina veterinária. Desta forma, o presente trabalho vem destacar não somente a importância da realização do LBA na identificação dos microrganismos envolvidos e suas respectivas sensibilidades e resistências aos antibióticos, como também demonstrar a importância do diálogo com os tutores quanto a administração, conservação dos fármacos e até mesmo sobre a interrupção do tratamento sem recomendação veterinária.

Palavras-chave: lavado broncoalveolar; antimicrobianos; uso indevido.

\begin{abstract}
Diseases of the lower respiratory tract are routine in the small animal clinic and have several etiologies and therefore require precision when identifying the agents involved, which will lead to appropriate pharmacological interventions on a case-by-case basis. Bronchoalveolar lavage (BAL) is an important diagnostic medium that can be used in animals with bronchopneumonia that do not respond to standard therapy. Although LBA is a simple technique, it is not routinely used in veterinary medicine. Thus, the present study emphasizes not only the importance of BAL in the identification of the microorganisms involved and their respective sensitivities and resistance to antibiotics, but also the importance of dialogue with owners regarding administration, drug storage and even discontinuation of treatment without veterinary advice.
\end{abstract}

Keywords: bronchoalveolar lavage; antimicrobials; inappropriate use.

\section{Introdução}

O sistema respiratório está em constante comunicação com o meio externo e seus agentes agressores e por isso, afecções pulmonares representam uma grande parcela dos atendimentos clínicos. Pneumonias infecciosas e neoplasias (primária ou por metástases) são causas comuns de doenças que afetam o parênquima pulmonar de animais de companhia (Reinero e Cohn, 2007).

Broncopneumonia é uma resposta inflamatória onde há intensa exsudação celular e presença de líquido nas pequenas vias aéreas e nos alvéolos. Essa inflamação ocorre na maioria das vezes, devido a proliferação de micro-organismos que residem na microbiota respiratória do próprio paciente e, portanto, atuam como agentes oportunistas, que se aproveitam de uma falha no sistema imune do hospedeiro (Brady, 2004). Muitos cães são afetados por bactérias gram negativas aeróbias, tais como: Escherichia coli, Pseudomonas spp., Klebsiella spp., Enterobacter 
spp., Pasteurella spp. e Bortedella bronchiseptica. Uma pequena parcela dos casos é causada por bactérias gram positivas, tais como: Enterococcus spp., Streptococcus spp. E, eventualmente, por Staphylococcus spp. A incidência de infecções por agentes anaeróbicos não é muito relatada, porém sabe-se que é de baixa prevalência (Dear, 2014).

Os sinais clínicos da broncopneumonia são variáveis dependendo da causa, severidade e da cronicidade do processo. A doença pode se manifestar de forma aguda ou crônica, sendo que o único sinal clínico observado inicialmente pelos tutores é uma tosse fraca. Com a progressão da infecção, os pacientes podem apresentar intolerância ao exercício, tosse produtiva, febre, anorexia, letargia, dispneia e, em casos mais graves, posição ortopneica e mucosas cianóticas (Côté, 2015).

O padrão ouro de diagnóstico é por meio do exame histopatológico. No entanto, esse exame diagnóstico raramente é realizado na rotina clínica, sendo os meios de diagnóstico preconizados a anamnese, exame físico, radiografia torácica e lavado broncoalveolar com isolamento e cultura bacteriana e fúngica. A coleta de amostras para cultura e antibiograma são indicadas o mais precocemente possível. Porém, em casos mais graves é recomendado o início imediato com antibióticos de amplo espectro, pois nesses pacientes a broncopneumonia pode evoluir rapidamente acarretando em prognósticos desfavoráveis (King, 2010).

O presente trabalho tem como objetivo relatar um caso de broncopneumonia refratária devido ao uso incorreto de antibióticos, tradicionalmente usado na rotina clínica, enfatizando a importância da conduta diagnóstica correta e o diálogo com os tutores a respeito dos cuidados na terapia instituída.

\section{Descrição do Caso}

Foi atendido no Serviço de Cardiologia e Doenças Respiratórias do Setor de Pequenos Animais do Hospital Veterinário da Universidade Federal Rural do Rio de Janeiro, um paciente canino, fêmea, SRD, com 10 anos de idade, com queixa principal de tosse fraca e produtiva, dispneia ao repouso e cansaço fácil.

No exame físico, a frequência cardíaca era de 136 bpm, a frequência respiratória de 24 mrpm, as mucosas apresentavam-se normocoradas e a paciente apresentava temperatura corpórea normal. Foi observado presença de cálculos dentários e ao se realizar o reflexo de tosse a paciente apresentava bastante sensibilidade e manteve a tosse por tempo prolongado, mesmo após ter cessado o estímulo.

Não foram evidenciadas alterações à palpação dos linfonodos e o teste do piparote foi negativo. $\mathrm{Na}$ palpação abdominal detectou-se hepatomegalia, enquanto que na avaliação do pulso femoral o mesmo encontrava-se normocinético. $\mathrm{Na}$ ausculta torácica, a paciente apresentou sopro sistólico em foco mitral grau II/VI e ruído expiratório aumentado, além da presença de ruídos descontínuos (crepitações) ásperos, principalmente em região ventral de lobos craniais esquerdo e direito.

Com base no histórico e na realização de um criterioso exame físico foram estabelecidas algumas suspeitas clínicas que poderiam condizer com a situação clínica da paciente.Estas foram: broncopneumonia, doença valvar degenerativa crônica de mitral e bronquite crônica. Para um diagnóstico mais completo e avaliação do estado geral da paciente foram solicitados exames complementares, que incluíram exames laboratoriais como, hemograma e bioquímica sérica, e exames de imagem como aradiografia torácica em três posições (ventro-dorsal, láterolateral direita e esquerda), e o ecodopplercardiograma.

O hemograma revelou apenas eosinofilia e a bioquímica sérica não apresentou alterações. Os achados radiográficos revelaram padrão bronquial e intersticial, sugestivo de broncopatia e padrão alveolar em lobos craniais (Figura 1), compatível com broncopneumonia.

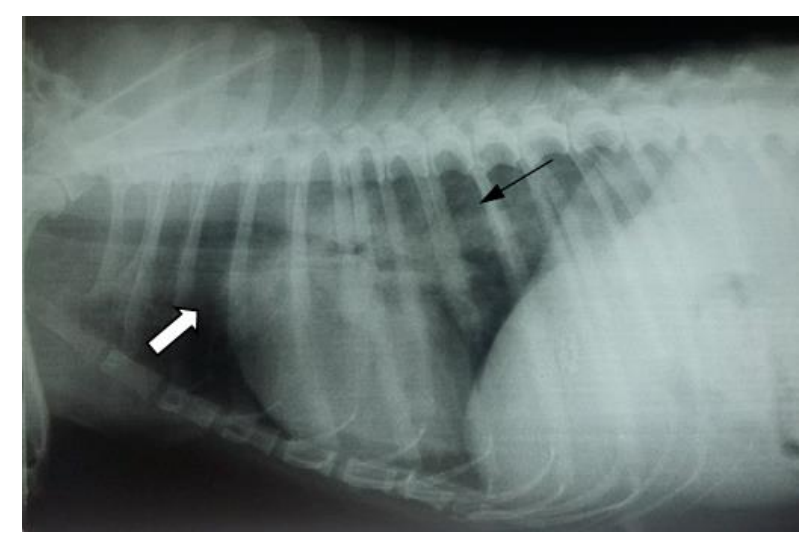

Figura 1. Radiografia torácica em posição látero-lateral esquerda evidenciando padrão alveolar em região dorso-caudal (ponta de seta) e cranial (seta preenchida).

O ecodopplercardiograma revelou válvula mitral levemente espessada com regurgitação discreta, relação átrio esquerdo/aorta de 0,99, 
fração de encurtamento do VE de $33,7 \%$ e presença de reverberações em todos os campos pulmonares. A partir desses resultados foram prescritos: aminofilina $(10 \mathrm{mg} / \mathrm{Kg})$ a cada 12 horas durante 30 dias; acetilcisteína xarope $(10 \mathrm{mg} / \mathrm{Kg})$ a cada 12 horas durante 21 dias e amoxicilina com clavulanato de potássio $(25 \mathrm{mg} / \mathrm{Kg})$ a cada 12 horas durante 30 dias.

Ao longo do tratamento, a paciente apresentava persistência dos sinais clínicos e foi recomendada a realização de lavado broncoalveolar para determinação do agente envolvido e sua sensibilidade à antibioticoterapia. A tutora mostrou-se relutante ao procedimento anestesiológico e, portanto, em dois meses de tratamento sem sucesso foi associado enrofloxacino na dose de $10 \mathrm{mg} / \mathrm{Kg}$ por via oral, a cada 12 horas.

Em um mês com o novo tratamento a paciente não apresentava melhora clínica e assim foi indicada a interrupção do tratamento por 15 dias para a realização do lavado broncoalveolar. A tutora neste momento concordou com a realização do procedimento (Figura 2), que foi feito às cegas, com a introdução de sonda até aproximadamente a região da carina, na qual foi instilado cerca de 10 $\mathrm{mL}$ de solução fisiológica estéril seguida de imediata aspiração, sendo este procedimento repetido para obtenção de diferentes amostras.

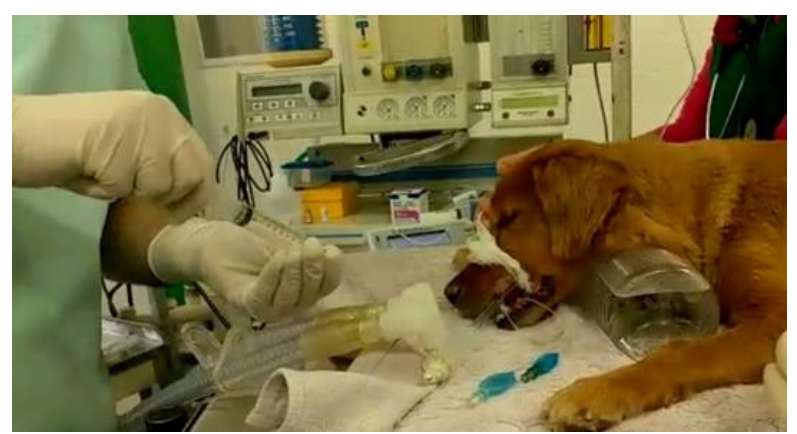

Figura 2. Paciente portadora de pneumonia posicionada em decúbito esternal com suporte em região cervical evidenciando a instilação de solução salina à $0,9 \%$.

Do material coletado foram realizados exame citológico, cultura fúngica, cultura bacteriana e antibiograma. A análise citológica era composta predominantemente por neutrófilos (em torno de $80 \%$ ), os quais variavam entre células degeneradas, hipersegmentadas ou normais. Também se observou eosinófilos (em torno de $15 \%)$ e presença de alguns macrófagos ativados. Não foi observada a presença de fungos ou bactérias nas amostras analisadas. No período em que se aguardava o resultado da cultura e antibiograma, o paciente apresentou piora clínica acentuada, sendo introduzido então levofloxacino na dose de $10 \mathrm{mg} / \mathrm{Kg}$ por via oral a cada 12 horas.

Cerca de 20 dias após a nova terapia instituída, a tutora relatou que a paciente estava mais ativa em casa, dormindo melhor e que houve redução na frequência da tosse, sendo que as crises só ocorriam após quadros de agitação. O resultado da cultura e antibiograma revelou presença das bactérias Escherichia coli e Staphylococcus schleiferi subps. coagulans, sendo que ambas eram sensíveis à amoxicilina com ácido clavulânico e a enrofloxacina.

\section{Discussão}

O achado radiográfico de padrão alveolar é condizente com a presença de pneumonia e, apesar de ser relatada maior ocorrência de padrão alveolar em lobos crânio-ventrais, podemos encontrar em lobos caudais, principalmente quando há disseminação hematógena e/ou infecção por via inalatória (Brady, 2004).

A terapia instituída inicialmente se deu com: amoxicilina com clavulanato de potássio, que é um antibiótico de amplo espectro; aminofilina, que além da broncodilatação confere maior depuração mucociliar, inibe a degranulação dos mastócitos e diminui o vazamento microvascular; acetilcisteína, que confere a quebra das ligações de dissulfeto presente no muco das vias respiratórias, além de ser precursora da glutationa, que tem papel de sequestrar os radicais livres associados ao processo inflamatório; nebulização com solução salina, que ajuda a hidratar o sistema mucociliar facilitando a expulsão do muco (Côté, 2015).

O LBA foi realizado com objetivo de identificar os agentes envolvidos na infecção, assim como garantir a escolha mais apropriada da antibioticoterapia, visto que a paciente não apresentava melhora com a terapia inicialmente instituída (Hawkins, 2002). Apesar da realização desse exame ser tecnicamente simples e rápida, sua utilização na medicina veterinária é pouco rotineira possivelmente por apresentar custos adicionais aos tutores, a necessidade de submeter o animal a um plano anestésico ou até mesmo por falta de indicação e inexperiência do médico veterinário em realizar o procedimento (King, 2010). Portanto, em muitos casos a escolha empírica dos antibióticos se torna rotineira, devendo ser baseada em trabalhos prévios sobre os principais agentes causadores de infecção e suas respectivas sensibilidades aos principais antibióticos (Martinez et al., 1996). 
$\mathrm{Na}$ análise citológica não foram observados fungos ou bactérias nas amostras analisadas. Entretanto, o diagnóstico de infecções do trato respiratório inferior é baseado geralmente nos achados clínicos e de cultura (Peeters et al., 2000). A infecção bacteriana pode ser resultado de uma ampla variedade de patógenos, e dentre os mais comuns podemos citar Escherichia coli e Staphylococcus spp., que foram os responsáveis pelo quadro infeccioso na paciente (Cohn, 2010). A maioria dos casos de pneumonia é ocasionada pela própria microbiota dos animais, sendo as bactérias gram negativas entéricas, os patógenos mais comumente associados a cães com pneumonia. Embora se relate que as infecções causadas por um único agente seja a forma mais comum de ocorrer, um estudo relatou que infecções causadas por múltiplos agentes bacterianos podem representar até $43 \%$ dos casos (Angus et al., 1997) e este fato pode tornar o tratamento mais demorado e o sucesso mais susceptível aos erros de administração por conta do tutor.

Apesar do antibiograma ter demonstrado sensibilidade aos antibióticos usados no tratamento da paciente, em quase dois meses a mesma não apresentava nenhuma melhora clínica evidente. A falta de melhora clínica pode ter ocorrido por uso inapropriado dos antibióticos por parte da tutora, seja por negligência em relação ao cumprimento dos horários e doses, ou por suspensão por conta própria. A terapêutica instituída com o levofloxacino, foi uma tentativa visto que é um antibiótico de amplo espectro amplamente utilizado em infecções pulmonares (Golan et al., 2012). Alguns animais acometidos com pneumonia não respondem a terapia convencional, e dentre eles se destacam os pacientes pediátricos, senis, imunocomprometidos ou com doenças de base, que são considerados os grupos de risco (Brady, 2004). A falha em responder ao tratamento convencional pode ocorrer por: uso/escolha inadequada da antibioticoterapia que podem resultar em resistência bacteriana, ou concentrações inadequadas do fármaco no seu sítio de ação, infecções virais e/ou fúngicas associadas, presença de lobos pulmonares consolidados ou abscessos, diagnóstico incorreto ou defeitos anatomofuncionais do próprio paciente quanto às defesas pulmonares ou ocorrência de sepse (Hoffman, 2012).

No presente relato, não foi identificada qualquer causa clínica que pudesse comprometer o sucesso terapêutico e, portanto, não foi encontrado motivo para a falta de resposta diante de uma correta antibioticoterapia contra agentes com sensibilidade comprovada posteriormente.

É fundamental que se estabeleça um diálogo franco com os tutores, ressaltando-se a importância do uso correto dos antibióticos, quanto às dosagens e horários de administração, como também quanto a interrupção do tratamento sem recomendação do médico veterinário, uma vez que estes fatores são determinantes para a resolução eficaz do quadro, contribuindo assim para a redução do desenvolvimento de resistência bacteriana frente as bases farmacológicas antimicrobianas

\section{Conclusão}

Diante da abordagem deste caso, conclui-se que cabe ao médico veterinário a escolha do protocolo terapêutico mais adequado a ser instituído para resolução eficaz do quadro, mas também a orientação e o convencimento sobre o uso responsável da antibioticoterapia por parte do tutor, evitando-se assim o desenvolvimento de resistência bacteriana e falhas na terapêutica instituída.

\section{Conflito de Interesse}

Os autores declaram não existir conflito de interesse.

\section{Referências}

Angus, J.C.; Jang, S.S.; Hirsh, D.C. Microbiological study of transtracheal aspirates from dogs with suspected lower respiratory tract disease: 264 cases (1989-1995). Journal of the American Veterinary Medical Association, 210(1): 55-58, 1997.

Brady, C. Bacterial pneumonia in dogs and cats. In: King, G.L. Textbook of respiratory disease in dogs and cats. St Louis: Saunders, 2004. p.412-421.

Cohn, L.A. Pulmonary parenchymal disease. In: Ettinger, S.J.; Feldman, E.C. Textbook of veterinary internal medicine expert consult. $7^{\text {th }}$ ed. California: Elsevier, 2010. p.743-746.

Côté, E. Pneumonia. In: Silverstein, D.C.; Hopper, K. Small animal critical care medicine. $2^{\text {nd }} e d$. St. Louis: Saunders, 2015. p.120-126.

Dear, J.D. Bacterial pneumonia in dogs and cats. Veterinary Clinics of North America: Small Animal Practice, 44(1): 143-159, 2014.

Golan, D.E.; Tashjian, A.H.; Armstrong, E.J.; Armstrong, A.W. Princípios de Farmacologia: a base fisiopatológica da 
terapêutica. $3^{\text {rd }}$ ed. Rio de Janeiro: Guanabara Koogan, 2012. v.1, 1008p.

Hawkins, E.C. Appropriate use of antimicrobials in respiratory tract infections. Proceedings Prague, 20th. American College of Veterinary Internal Medicine, 2002. Disponível em <http://www.vin.com/Members/Proceedings/P roceedings.plx ?CID=ACVIM2002\&PID=pr0> . Acesso em: 20 set. 2017

Hoffman, S. Mechanisms of antibiotic resistance. Compendium on Continuing Education for the Practising Veterinarian $\mathbf{2 3}^{\text {th }}$ ed, 5(1): 464473, 2001.

King, L.G. In: International Congress of the Italian Association of Companion Animal Veterinarians. Treating canine bacterial pneumonia: more than just antibiotics. Rimini, Italy, 2010. p.133-134.

Martinez, R.; Gironi, R.H.A.R.; Santos, V.R. Sensibilidade bacteriana a antimicrobianos usados na prática médica. Medicina, 29(1): 278-284, 1996.

Peeters, D.E.; Mckiernan, B.C.; Weisiger, R.M.; Schaeffer, D.J.; Clercx, C. Quantitative bacterial cultures and cytological examination of bronchoalveolar lavage specimens in dog. Journal of Veterinary Internal Medicine, 15(1): 534-541, 2000.

Reineiro, C.R.; Cohn, L.A. Interstitial Lung Diseases. Veterinary Clinics Small Animal Practice, 37(1): 937-947, 2007. 